\title{
No Library, No Problem: Engineering Solutions to Library Challenges
}

\section{Cari Lyle, University of Southern California}

Cari Lyle is the Science and Engineering Librarian at USC Libraries. Her primarily role is to serve as the liaison to the engineering and computer science departments. Having worked for years as a library paraprofessional, this is Cari's first professional role as a librarian and she is definitely jumping into the deep end! 


\section{No Library, No Problem: Engineering Solutions to Library Challenges}

State of the Library and Librarian

The University of Southern California (USC) maintains twenty libraries across two campuses. The Science \& Engineering Library is a satellite library that primarily serves the science and engineering departments on one campus. While majority of the libraries at USC have undergone a variety of changes including space reductions and staffing challenges in recent years, the Science \& Engineering Library has had to contend with these changes as well as a oneyear closure for spatial renovations. My goal with this paper is to provide a case study of how I, as a new librarian (new to the profession and to that specific library), approached these challenges and engineered solutions for the short and long term.

In my desire to properly address these challenges in my new work environment, I looked for frameworks to help organize thoughts, plans, and goals in order to be solutions oriented and forward thinking. Solution-focused therapy, while primarily applied in the field of psychology, has also been applied to organizational studies and workplace culture as it emphasizes coaching, finding cooperation, feedback, conflict resolution, and situation management [1]. This framework provided a method to rank problems, identify factors outside of my or my unit's control, and craft solutions [2]. This model was originally appealing because it provided a framework for discussing these problems with my entire unit; by emphasizing solutions, cooperation, and feedback, the Science \& Engineering Library was able to rebuild morale and project plan. Environmental scanning proved to be another useful technique in mapping out my work environment; it promotes assessment of internal and external factors that affect library 
operations [3]. Thus, this paper will feature how I assessed four main problems of staffing, library space, collections, and outreach, how I attempted to engineer solutions, and how I worked with my department to be solutions focused and forward thinking.

\section{Staffing}

Staffing remains a major challenge for the Science \& Engineering Library, with only one permanent librarian serving seven science and eight engineering departments. This library was once staffed with four librarians, which included a head librarian. Thus, as the solo librarian, I am tasked with liaison duties for all campus STEM communities, taking on a serious workload. While there is an acting head librarian, there duties are split with other liaison communities. In addition, the paraprofessional staff is made up of one library manager, three permanent library supervisors, and one contract library supervisor. Because this particular library has been closed for renovations, staff have been asked to assist the circulation desks of other campus libraries (highlighting that staffing shortages plague the entire library system).

One of the main challenges of hiring more librarians is that staffing is often beyond the individual library's control. Positions need to be justified and approved by library administration and budget constraints affect what positions will be opened. Furthermore, current efforts to hire more librarians have been so far unsuccessful. The main solution to having a smaller number of people has been to continue being highly collaborative via learning, sharing, and working on projects to create a team atmosphere. Pham and Tanner highlight potential issues though with collaboration between paraprofessional staff and librarians, "Although the importance of collaboration between academics and library staff is widely accepted, collaboration is a complex 
concept, representing a high level of human relationship, and there are many potential barriers to developing effective collaborative partnership" [4]. At this university, there is a division of responsibilities, requirements, and expectations for faculty librarians and paraprofessional library staff, so navigating a fair balance of work along with providing opportunities for growth can be challenging. Specifically, increasing the workload of staff to include reference and instruction duties can be seen as unfair, as those tasks are usually designated to librarians. However, some staff have their MLIS degree or are in MLIS programs and want the experience of reference and instruction, so providing those opportunities is sometimes welcomed. Therefore, as workloads have been increased, it is evident that individuals need to be consulted about how they are able to perform their assigned duties in addition to possible picking up more tasks. Overall, though, staff at the Science \& Engineering Library have been eager to assist in my responsibilities of creating research guides, designing exhibits, and editing a monthly newsletter, for example. Collaboration was not a priority in the past, but our team has worked to maintain open communication and cooperation.

The first solution to this staffing shortage, then, has been for everyone to take on a larger workload. While not ideal, it has been necessary in order to maintain services and working relationships with the science and engineering departments. For example, I was originally hired to liaise only with the school of engineering, which houses seven engineering and one computer science department. However, without other librarians to serve the science departments, I have added seven science departments to my workload. This means that instruction, reference inquiries, and research guides are mainly handled by one person. However, as mentioned above, due to the highly collaborative nature of our library, library staff assist in dividing and 
conquering new tasks. This increased workload has actually provided me, as the only librarian, opportunities to build new relationships and reinforce collaborations with departmental faculty that had somewhat waned due to high librarian turnover.

The second solution identified is to maintain our current internship program at the Science \& Engineering Library. Our temporary, acting head librarian began an internship program to help develop students professionally from both the university library program as well as external library and information science programs. Practically speaking, interns do not need the same requirements for full-time faculty or staff positions, so the Science \& Engineering Library has been able to regularly hire interns each semester. Interns assist with updating research guides, creating flyers, handouts, and slides for instruction, and assist with reference. Interns have aided the library immensely, contributing diverse perspectives and picking up tasks where needed. Having interns has contributed to the collaborative atmosphere and has allowed for the library to keep providing services to their communities and grow professionally as well as a team.

Staffing directly affects the library's goal of serving the science and engineering departments. Specifically, having more librarians means that more attention can be given to individual departments, allowing for professional relationships to grow. An immediate outcome of more librarians means that we could create and enact new initiatives. For example, with the current library renovations, the staff and I have been interested in reconceptualizing old spaces into areas with makerspaces and/or virtual reality (VR) technologies. Having more librarians means that current workloads would be better balanced to allow for time to research these 
technologies and establish an action plan. This relates to being able to expand outreach programs as well. With more librarians and new library spaces, we could host trainings, student group events, and mindfulness activities. This all connects to the original goal of serving the science and engineering departments via reference, instruction, outreach, and new programming.

Space

The physical space of library, like staffing, requires compromise between the Science \& Engineering Library and library administration. Because renovations were planned in advance, many of the decisions about library space happened before I was hired. My assessment of this challenge, then, is from a lens of future planning. The Science \& Engineering Library is being reduced in size from three floors to two floors, as the school of engineering will build a makerspace on the first floor. This mean that the library space has been undergoing renovations, downsizing print collections, moving staff spaces, and reorganizing furniture. More importantly, this means less study spaces for students and a change in direction for the library. With print collections reduced and space restructured, though, the librarians and staff have redirected efforts to investigate how the spaces left can be utilized to provide better services and programs.

The main objective identified by the Science \& Engineering Library was to reimagine the new library space and make efforts to modernize space and programming. Space encompasses many aspects, such as the physical collection, study rooms, technology available, and staff work areas. Academic libraries in general are reevaluating their spaces and services to adjust to modern trends and student needs. Coined as "Next-Gen learning spaces", Choy and Goh define, "Next-Gen learning spaces are service-rich environments created in collaboration with campus 
partners that support active learning and multidisciplinary instruction along with providing a platform for scholarly communication and culture enrichment" [5]. This concept provided the foundation to view this challenge through a positive lens. A primary goal for the Science \& Engineering Library is to create a partnership with the school of engineering's makerspaces on the first floor of the same building. This would allow the library to utilize the makerspaces and create instruction and workshop sessions. Building from there, we hope to incorporate some makerspaces technologies or emerging technologies into the physical library itself. Assessing what technology will be available in the engineering makerspaces will highlight where the library can complement services and technologies.

As a new librarian, I conducted an environmental scan of all other makerspaces on campus. This highlighted the extreme variation in not only available technologies, but also accessibility. Makerspaces across campus hosted an array of equipment, but accessibility was often tied to being associated to specific majors, departments, student organizations, or classes. Thus, the Science \& Engineering Library hopes to help fill this gap by offering popular and necessary equipment to all students on campus. In fact, this environmental scan brought to my awareness another satellite library's makerspace. My hope is to partner with this library makerspace to provide more students with access to makerspaces equipment and emerging technologies. Other ideas for this renovated library spaces include a STEM-related board game collection and VR stations. Game development is a popular field of study at USC, so having alternative methods for students to learn through play as well as offer mindfulness activities will demonstrate how the library is student-focused in their usage of spaces. 
Also, the current solution to not having a physical space has been to be active and partner in library-wide initiatives. This includes partaking in reference duties at the main branch library, teaching instruction to non-discipline specific audiences such as graduate or international student populations, and pop-up library services across campus. The other satellite libraries host a variety of events that demonstrate the ability for librarians and library staff to collaborate across the libraries and with students from all disciplines. Participating in these library-wide events demonstrates ways to share knowledge and best practices that I hope to carry into our new space.

\section{Collections}

Because of the reduction to physical library space, print collections were severely decreased. One of my first tasks as the new librarian was to assist with an already-implemented weeding project. Based on specific criteria, like items published in the last ten years, circulation history within five years, and call number ranges that matched critical science and engineering disciplines, we discarded items, sent items to off-campus storage, and marked items to return once the library reopened (these were sent to another satellite library). Simultaneously, the Science \& Engineering Library was tasked with conducting analysis on online journal and database subscriptions as the entire university library system was transitioning to an e-preferred acquisitions model.

We foresee the need to bring back books sent to off-campus storage to rehouse in the newly renovated library, as we have more shelving than originally anticipated. The biggest challenge in the post-weeding months has been to increase public awareness of our collections. At outreach events, we work to make students and faculty aware that our print collections are 
temporarily housed at another satellite library on campus during our closure. I also strive to highlight our robust eBook collection in our monthly newsletter to demonstrate the variety of the collection, the accessibility of online material, and the frequency in which we receive new books. In planning for the future, the Science \& Engineering Library has plans to display new books in the new library shelving spaces as well as exhibits featuring special collections and STEMrelated popular reading.

The weeding project and collection analysis has been quite fruitful as it allows us to cull the collection and conduct inventory projects. Once the library is reopened and the print collection is back in the library, we hope to develop an internal collection development policy. This would solve, or at least, make less difficult future weeding projects. Ideally, weeding and collections analysis projects would occur regularly, so that it becomes routine collection maintenance. A written policy will highlight the criteria used to weed, how long materials should remain on new book display shelves, and journal and database subscription information, for example. This would ensure staff and librarians are kept up to date and provide continuity during staffing changes. While the university library system as a whole has a collection development policy, an internal policy specific to the Science \& Engineering Library would allow us to be better equipped for collections projects and to cultivate our print collections for our STEM campus communities.

\section{Outreach}

Due to librarian turnover and staff shortages, it has been difficult to maintain and develop relationships with the science and engineering departmental faculty. Furthermore, because the 
library is closed for renovations, librarians and staff are not located in the science and engineering area of campus. Thus, outreach has been a focus point as the team has been exploring opportunities in the short term and planning for the future in order to bolster relationships and provide services to the science and engineering campus communities. The university library system maintains a liaison librarian model, pairing librarians with specific disciplines on campus; the librarians are expected to develop subject expertise, teach information literacy, and understand the research needs of their respective communities. Librarians are also tasked with promoting and marketing the university libraries and library services, acting as a library advertiser [6]. Librarians wants to engage with their users, facilitating the sharing of ideas and input.

The librarian and staff are already actively engaged in library-wide outreach activities, working to demonstrate to the STEM students that even though the physical library is temporarily closed that they can still access collections and work with the librarians and staff. These outreach activities include Librarian Ask Me Anything as well as external activities like engineering orientations and university welcome events. As an example, Lunch and Learn with a Librarian for International Students workshops allowed me to not only engage with international students studying all disciplines, but specifically introduce myself and our library services to international students studying the science and engineering disciplines. Participating in these library, departmental, and campus events remain an important part of our outreach and engagement plans and will continue even after we are in our own space and able to develop some of our own programming and services like board game nights and VR stations. 
We also created a monthly newsletter to alert users that the library is still providing services, purchasing new books, and hosting events and workshops across all the libraries. This has been the first future-focused solution to our outreach challenges; it allows us to remain relevant despite not having a physical space. In preparing for the newsletter, I, as the editor in chief, connected with each science and engineering department managers to curate a list of contacts for the newsletter and discussed the best ways to disseminate information to those communities. This has provided new communication channels and a foundation for rebuilding relationships.

\section{Conclusion}

Being solutions-oriented provided a framework to work through library challenges and establish plans for moving forward. It boosted morale and fostered a creative and collaborative environment. The Science \& Engineering Library, in particular, faced challenges in the areas of staffing, space, collections, and outreach and strived to engineer positive solutions and investigate new trends worth incorporating. It is important that a science and engineeringfocused library remain innovative and user-centric to not only keep up with their communities, but also to explore new ways of providing services and programs to push the boundaries of what libraries can do in the future. Having short-term and long-term solutions also provided achievable goal setting. Those long-term goals will set the foundation for strategic planning upon reopening, so that there is minimal to no gaps in services and programs. Ultimately, this paper demonstrated how a new librarian attempted make sense of her work environment and engineer solutions to challenges, which can be adopted by others experiencing similar concerns. 


\section{Bibliography}

[1] A. J. Macdonald, "Solution-Focused Approaches in the Workplace," in Solution-Focused Therapy: Theory, Research, \& Practice, London, Sage Publications, 2011.

[2] A. J. Macdonald, "Introduction," in Solution-Focused Therapy: Theory, Research \& Practice, London, Sage Publicatios, 2011.

[3] J. Castiglione, "Environmental scanning: an essential tool for twenty-first century librarianship," Library Review, vol. 57, no. 7, pp. 528-536, 2008.

[4] H. T. Pham and K. Tanner, "Collaboration Between Acdemics and Library Staff: A Structurationist Perspective," Australian Academic \& Research Libraries, vol. 46, no. 1, pp. 2-18, January 2015.

[5] F. C. Choy and S. N. Goh, "A Framework for Planning Academic Library Spaces," Library Management, vol. 37, no. 12, pp. 13-28, January 2016.

[6] I. D. Silver, "For Your Enrichment: Outreach Activites for Librarian Liaisons," Reference \& User Services Quarterly, vol. 54, no. 2, pp. 8-14, January 2015. 